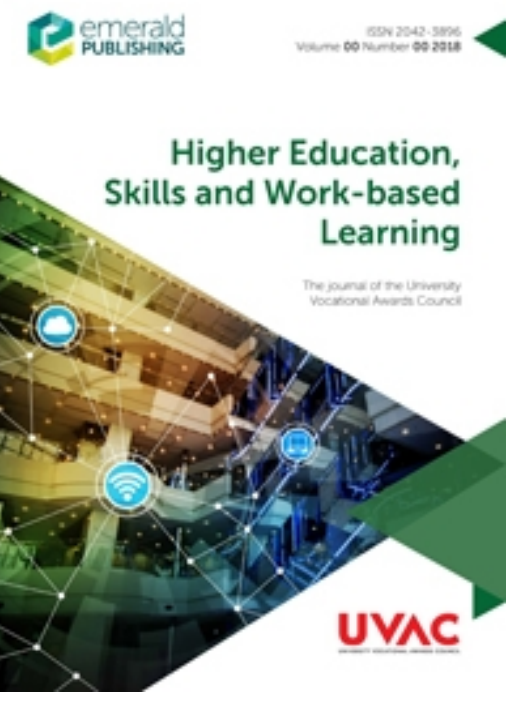

\title{
Constructive and negative aspects of social capital in work- related learning networks
}

\begin{tabular}{|r|l|}
\hline Journal: & Higher Education, Skills and Work-Based Learning \\
\hline Manuscript ID & HESWBL-08-2019-0104.R1 \\
\hline Manuscript Type: & Research Paper \\
\hline Keywords: & $\begin{array}{l}\text { Social Capital, Work-Related Learning, Network, Networking, Qualitative } \\
\text { case study, Learning Factor }\end{array}$ \\
\hline \multicolumn{2}{|l}{} \\
\hline
\end{tabular}

\section{SCHOLARONE \\ Manuscripts}




\section{Abstract: Constructive and negative aspects of social capital in work-related learning networks}

\section{Purpose of this paper}

The purpose of this paper is to discuss empirical findings from a study that investigated the work practices within an education network, with the aim of understanding the processes of knowledge development and learning process

\section{Design/methodology/approach}

The research is interpretatively positioned through a qualitative case study methodology. This enabled a holistic portrait of the network activity using three different methods of data collection. These were a preliminary focus group, followed by documentary analysis of a significant number of artefacts/documents produced by the network which were triangulated with data from interviews using a cross-case analytical framework.

\section{Findings}

Empirical insights are provided into how the practice of the network functions through a lens of social capital. It suggests that having a strong bonding social capital is an informal learning factor which develops the individual participants' skills and knowledge within the framework of Boyers' scholarly practice. The findings also indicate a 'dark side' to this informal learning factor which impeded collective learning through exclusivity and a maintenance of the status quo within the network.

\section{Research limitations/implications (if applicable).}

Because of the chosen research approach, the research results may lack generalisability. Therefore, researchers are encouraged to test the proposed propositions further.

\section{Practical implications}

The paper considers social capital within a network and the implication that this has on learning and development.

\section{What is original/value of paper What is new in the paper?}

This paper provides insight into informal learning factors employed within work-related learning and the duality of social capital. It also offers a novel approach in understanding how nurse academics frame work-related learning through scholarly practice. 


\section{Constructive and negative aspects of social capital in work-}

\section{related learning networks.}

\section{Introduction}

This paper presents findings from an exploratory study of a European Nurse Education Network that investigated the work practices of the network with the aim of understanding what and how members of a professional network learn both together and individually. Recent literature indicates the importance of understanding sociocultural practices within work communities, including professional networks, that can enhance learning (Field, 2013; Fleming and Haigh, 2018; Nevalainen, Lunkka and Suhonen, 2018). Social capital is applied here as the theoretical lens to explore the sociocultural practices of the network including the nature of the relationships and collaboration between its members to illuminate how these factors contributed to the learning and professional development of the participants in the study.

\section{Networks and social capital}

Networks establish connections and provide opportunities to engage in professional dialogue, exchange resources and share good practice to address common professional concerns but the nature of the connections which sustain a network are poorly understood (Bienzle et al., 2007). Even network co-ordinators within prominent networks show little understanding of how these work or the approach needed to ensure their success (Sousa, Doroftei and Araújo, 2013).

Nevertheless a successful network can lead to benefits for all the organisations and individuals involved such as capital enhancement and collaborative advantage (Connolly, Jones and Jones, 2007; Wakefield and Dismore, 2015). Collaborative advantage is defined by Huxham (1996) and Huxham and Vangen (2005) as a collective beneficial outcome resulting from two or more organisations collaborating that may not have been achieved otherwise. Successful collaboration may result in a range of accrued benefits, with explicit outcomes such as direct organisational improvement or resource increase in one or more organisations, whilst some benefits are less obvious and are perceived as 'value added ' within an organisation (Huxham, 1996; Baum and Rowley, 2008). These are manifested at an individual level and include the opportunity for career choices, support and skills development (Baum and Rowley, 2008; Donert et al., 2011; Koschmann and Kuhn, 2012; Wei, Chiang and $\mathrm{Wu}, 2012)$. These latter advantages result from individuals experiencing learning or professional development because of constructing, accessing and exchanging knowledge with one another within a network (Muijs, West and Ainscow, 2010; Donert et al., 2011; Wakefield and Dismore, 2015). This informal learning occurs as a by-product of interaction between employees within a working group, and it relies on participation in work processes and developing relationships with others that have an action focus (Eraut, 2007).

However participants' behaviour may also influence collaborations negatively with the possibility of 'regress [ing] into a state of collaborative inertia' (Huxham and Vangen, 2005 :31) The impact of 
collaborative inertia results in networks becoming less productive, unambitious and maintaining the status quo with a consequent negative outcome on learning and professional development. Factors that may contribute to collaborative inertia include power relations at the organisational and individual level, these difficulties relate not only to judging who has the ability to influence and enact the network's agenda but how different events and actions of others are interpreted (Vangen and Huxham, 2010). Power differentials can therefore influence how trust is, or is not, built within a network, this is significant as trust is regarded as an essential ingredient of a successful network (Vangen and Huxham, 2010). Positive interactions within a network community rely upon trust, equity and reciprocity that enhances social capital and thus shapes the quality of the network and the learning that occurs within it (Casey, 2011; Putnam, 2000). The concept of social capital is not new with a range of specialist literature in this field and notable theorists who have explored the concept in depth (Coleman, 1988; Bourdieu and Wacquant, 1992). This paper bases the notion of social capital on one of the most prominent theorists in the field, Putnam (1995). He provides clear distinctions between the positive and negative impact of social capital and this is pertinent to outcomes of work-related learning networks.

Putnam (1993) defines social capital as "the features of social organization such as networks, norms, and social trust that facilitate coordination and cooperation for mutual benefit" (167). The interrelated features of trust, networks and norms are essential aspects of social capital. Trust facilities cooperation, and the more individuals trust others and feel that this trust is reciprocated the greater the likelihood of cooperation between them, for example within a nursing network. Reciprocity is key within a network because if participants believe that 'good acts' or pro-social behaviour will be reciprocated at a later point social capital will be enhanced (Field, 2013). Whilst personal interactions within a network enable someone to learn about the trustworthiness of another, the network is important to allow information about a person's trustworthiness to travel more widely (Vangen and Huxham, 2010). Furthermore, the denser the social interactions the greater the social capital within a network that can foster robust norms of reciprocity and sustain information about past collaborative success. Strong social capital also results from flatter or more horizontal network structures whereas hierarchical networks detract from it. Social capital as an explanatory framework also considers the connections within networks as a form of capital that link the micro level of the individual and the meso level of the network (Field, 2008). Putnam (2000) identifies various distinctions of social capital, firstly there are looser ties known as bridging capital which relies upon more remote connections with a focus on gathering contacts and access to information with minimal interaction and support. Secondly is bonding social capital which provides a more intense form of support (Halpern, 2005). Putnam (2005:23) suggests that bonding and bridging are not 'either-or' categories but rather 'more or less' dimensions which can exist within a single network.

Social capital as defined by Putnam (1993) was therefore used to understand how the network and its practice in this study could be understood, it was used as a lens to examine participants' practice and their accounts of their learning and professional development as a result of participating in the network.

\section{Nurse educator networks}

Network activity is common within the nurse education sector particularly across Europe with established networks claiming to share knowledge, resources and support (Koskinen et al., 2012b; 
Burgess, Reimer-Kirkham and Astle, 2014; Coates and Fraser, 2014). This has evolved from the internationalisation agenda of Higher Education Institutions with universities using such network engagement to globalise their university (Ottewill, 2005; Coryell et al., 2012; Wakefield and Dismore, 2015). Universities rely on these networks and collaboration to expand through increasing strategic advantage and provide wider educational opportunities for their students and staff, which also includes transnational opportunities (Donert et al., 2011; Fell, Fell and Kyoung, 2012; Wakefield and Dismore, 2015). These influences are also significant within the field of nurse education (Law and Muir, 2006; Koskinen et al., 2012a; Burgess et al., 2014).

Organisations in the educational and health care sector perceive that networking conveys collaborative advantage and improves collective agency (Koschmann, Kuhn and Pfarrer, 2012). However, for an educational network to be successful there is a requirement to have some form of process orientated structure which includes a common focus that all participants agree with, a clear governance structure and communication strategy. Muijs (2011); Azorín and Muijs (2017) identify the need for structured working and quality assurance, otherwise poor performance or weak collaboration by any organisation involved can lead to a failure of the network. Furthermore, there is an expectation that participants are motivated to engage with the networking partners so that strong equitable and inclusive relationships are created (Bienzle et al., 2007; Muijs et al., 2010; Casey, 2011; Sousa et al., 2013; Ovseiko et al., 2014). However commitment to the network is not enough if the power dynamics are unbalanced (Huxham and Vangen, 2005) with the result that the network does not achieve its full potential and at worst becomes dysfunctional. On the other hand, the features of effective networks are synergistic with other socially functioning groups that display high levels of social capital (Muijs et al., 2010).

\section{Outcomes and value of participating in a network.}

There are clear resource benefits from developing collaborative advantage and sharing of resources across networks. Networks also have other benefits which are learning and innovative in focus with an emphasis on professional development for individuals involved (Wakefield and Dismore, 2015), this is perceived to result in organisational improvement (Muijs et al., 2010). Certainly professional development from engaging in networks has been identified as being influential in developing academic practices within schools and the Further Education sector (Centre for the Use of Research and Evidence in Education, 2005; Appleby and Hillier, 2012). Members within this network are identified as nurse educators, this term is used as it encompasses the range of titles used globally for the role which include nurse academic, nurse teacher, nurse lecturer and nurse faculty member. The nurse educator in this context is a person who delivers and oversees education predominately delivered in a higher education setting or equivalent. For the purpose of this study, informal learning or professional development is framed with the concept of scholarly practice which is based on the definition by Boyer (1990) who proposed that within higher education a broader perspective of 'scholarship' should be used rather than the dualism of teaching/research. The nurse educator undertakes many other activities as part of their nexus of practice which includes cross boundary activity such as working in teams, having a clinical focus and quality assurance. The broader term of scholarly practice acknowledges a broader approach whereby research, scholarship, teaching and learning are part of one seamless whole (Boud and Brew, 2013b). Scholarly practice has four distinct yet overlapping meanings: the scholarship of discovery, the scholarship of integration, the 
scholarship of application, and the scholarship of teaching; this perspective has been supported by the American Nurses Association (American Association of Colleges of Nursing, 1999).

\section{The study}

The purpose of this study was to explore the working practices of a European Nurse Education Network which involved investigating the nature of the relationships and collaborations established within the network, with a scrutiny of how this may facilitate learning and professional development of the members. In this context the network refers to face-to-face encounters as well as online correspondence between member.

\section{Research design}

This research is positioned within an interpretive paradigm with interpretivism being the conceptual anchor whereby assumptions of knowledge are constructed through lived local experiences and through interactions with others. This paradigm also recognises the influence the researcher has on the interpretation of the situation (Guba and Lincoln, 1989). Interpretivism guided the methodology of this embedded single case study which adopted an iterative and holistic design involving three stages (Yin, 2014).

\section{The case}

In this research the single case was the network with data gathered over a two-year period where all members within the network at the time were within the bounded unit and invited to participate. The longitudinal nature of the case study allowed an in-depth understanding of the situation to develop and the opportunity to explore different perspectives over time (Hamilton and CorbettWhittier, 2012).

\section{Data Collection Methods}

The first stage utilised a focus group that assisted in framing the subsequent stages of data collection and to gain an understanding of how participants conceptualised the network. The focus group enabled the participants ' world views, both individually and as a group, to be gathered about their opinions of the network, and the meaning it had for them. To gather this information, a structured focus group schedule was used with the findings framing the second stage of data collection.

The next stage analysed the documents that were created by the network which offered the opportunity to explore and appraise meaning that was attached to these items. The analysis included an interpretation of the written practices of the individuals, as well as their relationships with each other and the community. The documents such as annual meeting minutes and guidelines were authentically composed by the participants; a purposeful sample of the documents were analysed based on the critical moments of the lifespan such as new leadership or a change of governance processes or increased student activity (Mcculloch, 2004).

The final stage of data collection utilised semi-structured interviews with self-selected members of the network. This method offered the opportunity to understand the experiences and perceptions of the nurse educators involved in the network using a naturalistic and interpretative framework (Rubin and Rubin, 2005; Denzin and Lincoln, 2013). 


\section{Participant sample in the research}

All members of the network (approximately 30 ) were invited to contribute to the focus group and interviews via email; data collection was undertaken during the annual meetings of the network. The focus group participants involved eight self-selected members from a range of countries, all with a range of experiences. There were a further eight volunteers for the semi-structured interviews with five of the sample having participated in the focus group as they felt that they wanted the opportunity to continue to discuss their perspectives in more depth.

\section{Data Analysis}

Data were collated at different stages and all data was imported into NVivo 10 software (Qsr, 2013) and analysed iteratively. Sets were coded to manage this data as it facilitated the development of interpretations by keeping track of ideas as they occurred and assisted with organising and displaying the data. A cross-case analysis was undertaken with the data sets whereby duplication of categories was considered, noting relations of variables identified with potential themes explored. Thematic analysis was supported by Braun and Clarke (2006).

Approval was gained from the university ethics committee with special attention paid to informed consent; minimizing the potential for coercion and ensuring privacy and confidentiality.

\section{Findings}

Three clear themes emerged from the data which are a) the practice of network, b) the participants' learning, c) exclusivity and status quo. The first theme frames the latter two due to the suggested influence of by-products from engaging in the practice of the network on participants learning and the exclusivity exhibited by the network.

\section{Practice of the network}

Practice in this context relates to the activity within the network which enables the network to function to sustain itself. The practice of the network has produced artefacts, rituals and rules all of which have structured the workings of the network, as such these have become significant as a framework to sustain the network activity. The collective nature of the group is identified as important and is given value by the network through the requirement to deliver and attend annual meetings; these meetings have a focus on processes within network activity rather than a wider strategic network development. Wider literature suggests that this activity reflects a structure of a transnational co-operative project rather than strategy focused networks which have been more traditional across Europe (Bienzle et al., 2007).

Early focus group data provided a portrait of this network which suggested the activity to be underpinned with a purpose of pragmatism and function which was responsive to the needs of the individual organisations involved in securing student exchange opportunities. This was reinforced by individual perceptions of how the network functions: 


\begin{abstract}
'My point of view, the whole idea of the network is to give students the opportunity to gain some experience. So, I think that's really what we're aiming for. Giving students this opportunity. 'Int-1: $\mathbf{2 3}^{\mathbf{1}}$
\end{abstract}

Through the collective of the network collaborative advantage has been established to secure placement provision across a range of providers, and the focus of the network has been to sustain and focus this activity. The documentary analysis reinforces this with evidence of governance and organisational structures which have evolved over time and have become embedded within the practices. These are the artefacts, rituals and rules which have become an integral aspect of the network practice. They have been instrumental in the achievement of student exchange rather than in achieving other espoused aims of research collaboration which are often cited within strategic networks. A key activity of this network has been the annual conferences which serves to monitor and reinforce the governance structures and embed a common understanding of the network across a range of members, organisations, cultural and political context. The annual meetings utilised formulaic rituals of showcasing individual organisations hosting the event particularly in countries where culturally hierarchy and associated status is important (Hofstede, 2001).

'Also, XXX, member of the XXX institution formally opened the conference, she then gave a presentation of the different facilities ' $X X X X$ Report: Section $1.01^{2}$

Artefacts produced reinforce these practices with the example being of the use of a 'handbook' outlining the rules and regulations of participation. This artefact is identified as being integral to the practice of network.

'And if we didn't have the handbook, I think it would all fall apart. It's all written, it hasn 't changed much` Int-1:45

These practices over time have served to create a specific type of culture associated to the network engagement and this was recognised by the participants in the interviews

'The Network is a system with its own way of going on and its own self-built culture. I think this has arisen to cope with the many differences`Int-2-66

Standardisation of process and practice was thought to be needed to be able to mediate the cultural and language differences that occur within a cross European network. However, this was not perceived by the participants as being useful with the notion that these artefacts and subsequent practice was problematic as indicated by this quote:

'The difficulties are that, even if we meet every year and we have this handbook, the cultural differences sometimes make it difficult' Int-4:70

Clearly working across different cultures was perceived as a challenge and was identified at times as being problematic within this network, even though various participants expressed frustration they

\footnotetext{
${ }^{1}$ Interviewee 1 : line number 23

2 Date/report: location in document
} 
appeared to accept the culture, rules, artefacts and practice of the network. Their frustrations seem to have been less important compared to the systems, structures and rituals of the network e.g. the structure of annual meetings.

\section{Connectedness and Social Capital}

The annual meetings provide the structure to develop connections and social capital and this ritual was identified as being important:

'Because that's why we meet every year, to make sure the network works' Int-1:25

That the relationships developed from a regular meeting alongside having the familiarity of systems, structure and rituals provides a sense of stability which serves to promote the practice of the network and subsequent exchange activity:

'Because it makes you feel comfortable. It makes you trust people. And if you trust people, it 's easier to give that trust to your students' Int-3:21

Trust is identified repeatedly both in the focus group and within the interviews as being essential for the practice of the network to success and as being key for the relationships to work. Trust has developed the collective responsibility and collegiate relationships. The following experienced participant reflects on her involvement with the network; how she perceived her interaction with members of the network by using terms such as 'feeling part' and 'together' that illustrate the existence of social capital, and collective responsibility, that is manifested within the network:

'I mean that people feel they are part of it, not just organising. They feel they really after a while you feel you kind of own the network together with the others' Int-4:23

There are clearly strong ties amongst the participants which serve to strengthen social capital, more specifically this is a form of social capital known as bonding capital. Bonding capital tends to occur across a homogenous and dense network of people and tends to be exclusive in providing support to members of the network (Putnam, 2000). This is illustrated by a sense of kinship described as being important, and that the regular meetings were an opportunity to meet ' cousins' (Int-1:23). This has been reinforced by the policies of the network as illustrated by the mentoring within the network

'XXX suggests a godmother/father/mentor system for new member' $\mathbf{2 X X X}$ report: Section 5.2

From developing mentoring and orientation to the network then bonding capital is created which serves as an intense form of support (Halpern, 2005), but in this particular network has created an interesting juxta-position of both positive and negative effects both created by strong bonding capital.

\section{Participant learning}

The findings from the focus group and the interviews identified a perception that professional development occurred due to the strong bonding social capital within the relationships.

'I think it's so fundamental. It's through being connected, that we learn, that we feel we are not on our own. But we learn a lot. It provides safety, its provided continuance. It provides the possibility to develop. To grow. ' Int-2: $\mathbf{1 1 8}$ 
This connectedness was perceived as providing intense support from the network for individual participants in their own professional domain, more specifically within the scholarship of integration and application which is solipsistic in nature and involves application to the practice of teaching (American Association of Colleges of Nursing, 1999). Participants identified that they entered the network hoping that they might develop their scholarly practice, and this has been expressed as an individual beneficial gain.

Across the network there was a sense of sharing of knowledge or scholarship in presentations related to professional nursing practice and from peers at the annual meetings. This is illustrated by the following example, and there is evidence of similar sharing at previous annual meetings with presentations included in the minutes:

'The Friday session began with an interesting talk given by Ms XXXXX, on the topic:

"Practice development - how to improve self -management support"?

20XX report: Section 13

These incidences appear to have had an impact on participants, with one participant reflecting in her interview on becoming more aware of a strand of developing academic activity:

'I don't know which conference it was but two or three conferences ago we had some world expert come and talk to us for an hour about global health. And that's something definitely that we don't have in our curriculum. We do health promotion. She was really good, this speaker. She was really good at showing how it does affect us and we do need to become aware, and perhaps we should be including it in our curriculum a bit more and more understanding` Int-6:128

Development of scholarly teaching is evident across the participant interviews which has been gained through observation, discussion and experiences within the network:

'You see different teaching styles; you see different approaches and we learn from each other. Int-3:228

'Two years ago, we were in XXX, and I saw their equipment and when I came back home I don't have the same equipment I try to do the same thing. And now in my teaching I'm using the equipment that is good. 'Int-5:212

The latter comment is relevant as it implies that prior to attending the network the use of teaching strategies may not have been used within the local curriculum. The same participant earlier indicated the need for their institution to gather different pedagogic teaching strategies as part of their involvement with the network. Other wider dimensions of learning occurred which is in alignment with scholarship or integration such as developing cultural awareness, personal learning and increased confidence. However, there was no recognition of learning from research activity. 
In summary, personal learning and scholarly development has occurred as consequence of strong bonding capital which has arisen from the practices within the network, and that social capital is a conduit for informal learning. This has been articulated as occurring predominately in three scholarly domains for each participant, with the potential to develop some in the fourth. Within this work context, bonding social capital is identified as a learning factor and integral for work related learning. Much of this learning appears to have occurred at a personal level in both confidence in trying new practices and developing cultural awareness and global understanding:

'So it's given me a broader view and personally being in the network has probably developed me in to being more aware`Int-1: 105

\section{Exclusion and collaborative inertia.}

These dense relationships can be problematic too, in this instance, having resulted in a practice within the network which is complex. Alongside the overt practices of the annual meeting and ceremonies, it has created a culture which is characterised by norms, values and expectations that are not explicitly articulated. There is an implicit nature of understanding of the network expected amongst the network participants. In this respect the network resembles a clan, or tribe with its collective and implicit understanding of what it means to belong to the group and this behaviour is common within professionals whereby hidden rules are in place to enculture newcomers to the profession (Becher and Trowler, 2001). This was perceived by the participants in interviews with the following quote which illustrates how newcomers are expected to take time to understand the implicit culture of the network the expected behaviour associated with this.

'You've got little cliques, and you're either welcomed in or you're not'. You do need to take time to integrate yourself and become aware of how the group works, how things operate before you go in and perhaps too heavy handed. 'Int-6:22

This participant felt that they needed to be accepted by the group with a hidden gatekeeping mechanism and rite of passage for admission to decision making. Those that do not understand the language or culture/rules of the group are then not able to contribute to any decision making, and they are essentially excluded. Certainly, in such groups with their strong social capital bonding there is a tendency for exclusivity and a reluctance to change its way of working, previously identified as collaborative inertia (Vangen and Huxham, 2010). The following quote identifies the established network practices that are not only complex and seemingly contradictory but that when new ideas are suggested about how to alter these practices it highlights the inertia to any change that may be suggested.

'But they want to do it in a particular way. They come in with a whole set idea that this is what they want to put forward to the network. But the way of working is, "Okay, bring it into the group work to discuss it, and be challenged about it and let us make it our own thing. As soon as something has been put upon it, the network almost explodes, like we don't want to have it. And that is, in itself an interesting thing. It's not only that we don't want it, but why are we so strong in opposing that way? And even to the point of, it's very hard to really talk about it'. Int-2:58 
This quote illustrates the collaborative inertia of the network which can occur when the power relations within the network disable the notion of openness, debate and cross-cultural compromise which can lead to hidden practices to avoid conflict. That consequently no new ideas are developed as illustrated by the limited expansion of the network over a number of years and perceived as inertia by the participants of the study.

'We don't go further on, new people are coming and I think it is naturally that new people are coming, but again the steps are not taken forward and this is more difficult so they do not stay`. Int-8:52

\section{Discussion}

Using social capital as a framework to understand the working practices and learning within a nursing education network is a useful approach, social capital is integral to the practice of this network and has been influential in its development and the learning exhibited by the participants. Understanding the network practice and activities mediated through social capital suggests that there is an ebb and flow of positive and negative consequences. Positive outcomes are the sustained partnerships within the network which maintains the practice of the network, a phenomenon which has been identified as important to maintain and sustain the network without financial capital (Billett et al., 2007; Dhillon, 2009). Social capital is positively associated with influencing high levels of performance or outcomes (Field, 2005; Halpern, 2005; Field, 2008). The network is productive in securing student placements across Europe in response to wider internationalisation antecedents. Finally, through the creation of social capital in the practice of the network, there is evidence of self-governance and distributed leadership, which contributes to sustaining practices.

More specifically social capital through the strong bonding capital established appears to create a learning milieu for the participants as a result of the trust created between participants. Being connected was identified by participants as being fundamental to their personal development and learning. Two specific sub-ordinate themes are relevant here; the first identifies that learning and professional development has been gained which is considered using Boyers 'scholarship domains (1990) and the second involves identifying what learning factors contribute to this. A learning factor affects learning either directly or indirectly and can be evidenced within formal learning settings such as the classroom or within informal learning settings such as a work context (Eraut, 2006). Engaging in this network is a work activity and provides an informal learning setting for its members, this network practice has provided opportunity for learning and academic practice (Cairns and Malloch, 2011; Boud and Brew, 2013a). Therefore, the European Nurse Education Network is providing an informal learning opportunity.

Social capital also has created an interesting juxtaposition in the network whereby the strong bonding capital established also has created negative consequences which appear to perpetuate exclusivity and compliance. Rituals and rules have been established whereby participants perceive they have had to adapt their behaviour to ensure they are accepted by the group and there is a need 
for compliance with cultural norms. A level of exclusivity is present which is managed by long term members to sustain the status quo. It is well understood that strong bonding networks which have limited external influence can develop coercive behaviours and occurs through a typology of compliance in relationships which have become established due to strong bonding social capital. (Field, 2008). Putnam (2000) describes this as being a 'dark side' of social capital which is present in this network. The static and enclosed nature of the network has led to an inertia and lack of growth and development which has created frustration for some of the participants. This has led to the network's activity being exclusive, homogenous and used for 'getting by 'rather than 'getting ahead' (Putnam 2000:23). Huxham and Vangen (2004) alternatively suggest that those who engage in multiple collaborative partnerships become fatigued by the multiple partnership activity expected of them which presents itself as an inertia within the partnership.

The ebb and flow of social capital indicates the equally negative and a positive effect on learning. In this case study, bonding social capital is a learning factor that enhances both learning and encourages a commitment to the network that has ensured some development in the scholarly practice of the participants (Hargreaves and Fullan, 2012). On the other hand, strong bonding social capital has simultaneously stifled the development of new ideas or new areas for learning. This is an interesting finding and contributes to the minimal understanding of the production and maintenance of social capital in the field of adult education and more particularly nurse education (Mcclenaghan, 2003; Field, 2008).

\section{Conclusion}

This research adds to the understanding of work-related learning theories; particularly where strong bonding social capital within a group exists and this appears to be influential on the learning of its members. Network activity in nurse education has not been significantly researched despite the plethora of networks in existence; therefore, these findings provide an interesting insight into how networks may function. It is recognised that further investigation of nurse education work practices is needed as this is identified as complex and unique with educators often experiencing feelings of uncertainty and isolation (Jackson et al., 2009; Duffy, 2012; Mcdermid et al., 2013; Mcdermid et al., 2016). This study offers a new perspective illustrating that bonding social capital could also be a useful resource to sustain nurse education networks and provide individual positive learning experiences. Through proactive development of social capital within partnerships and networks, activity could be sustained and become influential with the potential for positive outcomes. The findings also illustrate the risks of bonding social capital that creates embeddedness in conjunction with a reliance on internal self-governance that contributes towards exclusivity and inertia. The repercussions of this are that the network is bounded, without growth or evolution, and is exclusive and can be very difficult to enter for some prospective participants.

This small-scale study offers an insight into the importance of social capital as learning factor which is applicable for wide range of settings. Further research is needed in this field both to identify how social capital, which is created through work related activities and collaborative activities, may be a useful conduit to scaffold learning for learners not engaged in formal learning settings and to more fully understand the negative consequences of social capital that can lead to inertia and exclusion.

\section{References}


American Association of Colleges of Nursing. 1999. Defining Scholarship for the Discipline of Nursing [Online]. Available: http://www.aacn.nche.edu/publications/position/defining-scholarship [Accessed 14.11.16].

Appleby, Y. \& Hillier, Y. 2012. Exploring practice - research networks for critical professional learning. Studies in Continuing Education, 34, 31-43.

Azorín, C. M. \& Muijs, D. 2017. Networks and collaboration in Spanish education policy. Educational Research, 59, 273-296.

Baum, J. \& Rowley, T. 2008. Network strategy, Bingley, U.K, Emerald.

Becher, T. \& Trowler, P. 2001. Academic tribes and territories: intellectual enquiry and the culture of disciplines, Buckingham, The Society for Research into Higher Education \& Open University Press.

Bienzle, H., Gelabert, E., Jütte, W., Kolyva, K., Meyer, N. \& Tilkin, G. 2007. The Art of Networking, Austria, die Berater.

Billett, S., Ovens, C., Clemans, A. \& Seddon, T. 2007. Collaborative working and contested practices: forming, developing and sustaining social partnerships in education. Journal of Education Policy, 22, 637-656.

Boud, D. \& Brew, A. 2013a. Reconceptualising academic work as professional practice: implications for academic development. International Journal for Academic Development, 18, 208-221.

Boud, D. \& Brew, A. 2013b. Reconceptualising academic work as professional practice: implications for academic development. The International Journal for Academic Development, 18, 208.

Bourdieu, P. \& Wacquant, L. C. J. D. 1992. An invitation to reflexive sociology, Cambridge, Polity Press.

Boyer, E. L. 1990. Scholarship reconsidered: Priorities of the professoriate, Princeton, N.J, The Carnegie Foundation for the Advancement of Teaching.

Braun, V. \& Clarke, V. 2006. Using thematic analysis in psychology. Qualitative Research in Psychology, 3, 77-101.

Burgess, C. A., Reimer-Kirkham, S. \& Astle, B. 2014. Motivation and international clinical placements: Shifting nursing students to a global citizenship perspective. International Journal of Nursing Education Scholarship, 11, 75-82.

Cairns, L. \& Malloch, M. 2011. Theories of Work, Place and Learning: New Directions. In: Malloch, M., Cairns, Len., Evans, Karen. \& O`Conner, Bridget (ed.) The Sage Handbook of Workplace Learning. Sage.

Casey, M. 2011. Interorganisational partnership arrangements: A new model for nursing and midwifery education. Nurse Education Today, 31, 304-8.

Centre for the Use of Research and Evidence in Education 2005. Systematic research review: The impact of networks on pupils, practitioners, organisations and the comittess they serve., Nottingham, National College of School Leaders

Coates, K. \& Fraser, K. 2014. A case for collaborative networks for clinical nurse educators. Nurse Education Today, 34, 6-10.

Coleman, J. S. 1988. Social capital in the creation of human capital. American Journal of Sociology, 94, S95-S120.

Connolly, M., Jones, C. \& Jones, N. 2007. Managing collaboration across further and higher education: a case in practice. Journal of Further and Higher Education, 31, 159-169.

Coryell, J. E., Durodoye, B. A., Wright, R. R., Pate, P. E. \& Nguyen, S. 2012. Case studies of internationalization in adult and higher education: Inside the processes of four universities in the United States and the United Kingdom. Journal of Studies in International Education, 16, 75-98.

Denzin, N. K. \& Lincoln, Y. S. 2013. Collecting and interpreting qualitative materials, London, Sage.

Dhillon, J. K. 2009. The role of social capital in sustaining partnership. British Educational Research Journal, 35, 687-704. 
Donert, K., Hay, I., Theobald, R., Valiunaite, V. \& Wakefield, K. 2011. International collaboration in organizations promoting geography education: Exploring success and acknowledging limitations. Journal of Geography in Higher Education, 35, 445-455(11).

Duffy, R. 2012. Nurse to educator? Academic roles and the formation of personal academic identities. Nurse Education Today.

Eraut, M. 2006. Learning contexts. Learning in Health and Social Care, 5, 1-8.

Eraut, M. 2007. Learning from other people in the workplace. Oxford Review of Education, 33, 403422.

Fell, D. W., Fell, D. W. \& Kyoung, K. 2012. Developing international collaborations in physical therapy academia: a case example emphasizing education and scholarship.

Field, J. 2005. Social capital and lifelong learning, Bristol, Policy Press.

Field, J. 2008. Social capital, Abingdon, Routledge.

Field, J. 2013. Learning communities and imagined social capital: learning to belong. ABINGDON: ROUTLEDGE JOURNALS, TAYLOR \& FRANCIS LTD.

Fleming, J. \& Haigh, N. J. 2018. Using sociocultural insights to enhance work-integrated learning. Higher Education, Skills and Work-Based Learning, 8, 395-407.

Guba, E. G. \& Lincoln, Y. S. 1989. Fourth Generation Evaluation, Newbury Park, California, Sage.

Halpern, D. 2005. Social capital, Cambridge, Polity.

Hamilton, L. \& Corbett-Whittier, C. 2012. Using case study in education research, London, SAGE.

Hargreaves, A. \& Fullan, M. 2012. Professional capital: transforming teaching in every school, New York, Teachers College Press.

Hofstede, G. H. 2001. Culture's consequences: Comparing values, behaviors, institutions, and organizations across nations, Thousand Oaks, California Sage

Huxham, C. 1996. Creating collaborative advantage, London, SAGE.

Huxham, C. \& Vangen, S. 2004. Doing things collaboratively: Realizing the advantage or succumbing to inertia? Organizational Dynamics, 33, 190-201.

Huxham, C. \& Vangen, S. 2005. Managing to collaborate: the theory and practice of collaborative advantage, London;New York; , Routledge.

Jackson, C., Bell, L., Zabalegui, A., Palese, A., Sigurđardóttir, Á. K. \& Owen, S. 2009. A review of nurse educator career pathways; a European perspective. Journal of Research in Nursing, 14, 111122.

Koschmann, M. A. \& Kuhn, T. R. 2012. A communicative framework of value in cross-sector partnerships. The Academy of Management review, 37, 332-354.

Koschmann, M. A., Kuhn, T. R. \& Pfarrer, M. D. 2012. A Communicative Framework of Value in CrossSector Partnerships. Academy of Management Review, 37, 332-354.

Koskinen, L., Kelly, H. T., Bergknut, E., Lundberg, P., Muir, N., Olt, H., Richardson, E., Sairanen, R., De Vlieger, L., Medicinska Och Farmaceutiska, V., Uppsala, U., Vårdvetenskap, Medicinska, F. \& Institutionen För Folkhälso- Och, V. 2012a. European Higher Health Care Education Curriculum: Development of a Cultural Framework. Journal of Transcultural Nursing, 23, 313319.

Koskinen, L., Kelly, H. T., Bergknut, E., Lundberg, P., Muir, N., Olt, H., Richardson, E., Sairanen, R., De Vlieger, L., Vårdvetenskap, Uppsala, U., Medicinska Och Farmaceutiska, V., Institutionen För Folkhälso- Och, V. \& Medicinska, F. 2012b. European higher health care education curriculum: development of a cultural framework. Journal of transcultural nursing : official journal of the Transcultural Nursing Society / Transcultural Nursing Society, 23, 313-319.

Law, K. \& Muir, N. 2006. The internationalisation of the nursing curriculum. Nurse Education in Practice, 6, 149-155.

Mcclenaghan, P. 2003. Response to 'social capital: an analytical tool for exploring lifelong learning and community development'. British Educational Research Journal, 29, 435-439.

Mcculloch, G. 2004. Documentary research in education, history and the social sciences, London, RoutledgeFalmer. 
Mcdermid, F., Peters, K., Daly, J. \& Jackson, D. 2016. Developing resilience: Stories from novice nurse academics. Nurse Education Today, 38, 29.

Mcdermid, F., Peters, K., John Daly, J. \& Jackson, D. 2013. 'I thought I was just going to teach': Stories of new nurse academics on transitioning from sessional teaching to continuing academic positions. Contemporary Nurse, 45, 46-55.

Muijs, D. 2011. Leadership and organisational performance: From research to prescription? International Journal of Educational Management, 25, 45-60.

Muijs, D., West, M. \& Ainscow, M. 2010. Why network? Theoretical perspectives on networking. School Effectiveness and School Improvement, 21, 5-26.

Nevalainen, M., Lunkka, N. \& Suhonen, M. 2018. Work-based learning in health care organisations experienced by nursing staff: A systematic review of qualitative studies. Nurse Education in Practice, 29, 21-29.

Ottewill, R., . Riddy, P,. Fill,. K. 2005. International Networks in higher education: realising their potential. Horizon, 13, 138 - 147.

Ovseiko, P. V., O'sullivan, C., Powell, S. C., Davies, S. M. \& Buchan, A. M. 2014. Implementation of collaborative governance in cross-sector innovation and education networks: evidence from the National Health Service in England. BMC health services research, 14, 552-552.

Putnam, R. D. 1993. Making democracy work:civic traditions in modern Italy, Princeton, Princeton University Press.

Putnam, R. D. 2000. Bowling alone: the collapse and revival of American community, New York, Simon \& Schuster.

Qsr, I. 2013. Nvivo 10 for Windows [Online]. [Accessed 10.10. 2013].

Rubin, H. J. \& Rubin, I. 2005. Qualitative interviewing: The art of hearing data, Thousand Oaks, California, Sage Publications.

Sousa, S. B., Doroftei, A. O. \& Araújo, H. C. 2013. Networks in education: An analysis of selected discourses. Interchange, 44, 311-331.

Vangen, S. \& Huxham, C. 2010. Introducing the theory of collaborative advantage. In: Osborne, S. (ed.) The New Public Governance? Emerging perspectives on the theory and practice of public governance. London: Routledge.

Wakefield, K. \& Dismore, H. 2015. The role of transnational networking for higher education academics. Higher Education Research and Development, 34, 1281-1296.

Wei, L.-Q., Chiang, F. F. T. \& Wu, L.-Z. 2012. Developing and utilizing network resources: Roles of political skill. Journal of Management Studies, 49, 381-402.

Yin, R. K. 2014. Case study research: design and methods, London, Sage. 


\title{
Abstract: Constructive and negative aspects of social capital in work-related learning networks
}

\author{
Purpose of this paper
}

The purpose of this paper is to discuss empirical findings from a study that investigated the work practices within an education network, with the aim of understanding the processes of knowledge development and learning process

\section{Design/methodology/approach}

The research is interpretatively positioned through a qualitative case study methodology. This enabled a holistic portrait of the network activity using three different methods of data collection. These were a preliminary focus group, followed by documentary analysis of a significant number of artefacts/documents produced by the network which were triangulated with data from interviews using a cross-case analytical framework.

\section{Findings}

Empirical insights are provided into how the practice of the network functions through a lens of social capital. It suggests that having a strong bonding social capital is an informal learning factor which develops the individual participants' skills and knowledge within the framework of Boyers' scholarly practice. The findings also indicate a 'dark side' to this informal learning factor which impeded collective learning through exclusivity and a maintenance of the status quo within the network.

\section{Research limitations/implications (if applicable).}

Because of the chosen research approach, the research results may lack generalisability. Therefore, researchers are encouraged to test the proposed propositions further.

\section{Practical implications}

The paper considers social capital within a network and the implication that this has on learning and development.

\section{What is original/value of paper What is new in the paper?}

This paper provides insight into informal learning factors employed within work-related learning and the duality of social capital. It also offers a novel approach in understanding how nurse academics frame work-related learning through scholarly practice. 


\section{Constructive and negative aspects of social capital in work- related learning networks.}

\section{Introduction}

This paper presents findings from an exploratory study of a European Nurse Education Network that investigated the work practices of the network with the aim of understanding what and how members of a professional network learn both together and individually. Recent literature indicates the importance of understanding sociocultural practices within work communities, including professional networks, that can enhance learning (Field, 2013; Fleming and Haigh, 2018; Nevalainen, Lunkka and Suhonen, 2018). Social capital is applied here as the theoretical lens to explore the sociocultural practices of the network including the nature of the relationships and collaboration between its members to illuminate how these factors contributed to the learning and professional development of the participants in the study.

\section{Networks and social capital}

Networks establish connections and provide opportunities to engage in professional dialogue, exchange resources and share good practice to address common professional concerns but the nature of the connections which sustain a network are poorly understood (Bienzle et al., 2007). Even network co-ordinators within prominent networks show little understanding of how these work or the approach needed to ensure their success (Sousa, Doroftei and Araújo, 2013).

Nevertheless a successful network can lead to benefits for all the organisations and individuals involved such as capital enhancement and collaborative advantage (Connolly, Jones and Jones, 2007; Wakefield and Dismore, 2015). Collaborative advantage is defined by Huxham (1996) and Huxham and Vangen (2005) as a collective beneficial outcome resulting from two or more organisations collaborating that may not have been achieved otherwise. Successful collaboration may result in a range of accrued benefits, with explicit outcomes such as direct organisational improvement or resource increase in one or more organisations, whilst some benefits are less obvious and are perceived as 'value added' within an organisation (Huxham, 1996; Baum and Rowley, 2008). These are manifested at an individual level and include the opportunity for career choices, support and skills development (Baum and Rowley, 2008; Donert et al., 2011; Koschmann and Kuhn, 2012; Wei, Chiang and $\mathrm{Wu}, 2012)$. These latter advantages result from individuals experiencing learning or professional development because of constructing, accessing and exchanging knowledge with one another within a network (Muijs, West and Ainscow, 2010; Donert et al., 2011; Wakefield and Dismore, 2015). This informal learning occurs as a by-product of interaction between employees within a working group, and it relies on participation in work processes and developing relationships with others that have an action focus (Eraut, 2007).

However participants' behaviour may also influence collaborations negatively with the possibility of 'regress [ing] into a state of collaborative inertia' (Huxham and Vangen, 2005 :31) The impact of 
collaborative inertia results in networks becoming less productive, unambitious and maintaining the status quo with a consequent negative outcome on learning and professional development. Factors that may contribute to collaborative inertia include power relations at the organisational and individual level, these difficulties relate not only to judging who has the ability to influence and enact the network's agenda but how different events and actions of others are interpreted (Vangen and Huxham, 2010). Power differentials can therefore influence how trust is, or is not, built within a network, this is significant as trust is regarded as an essential ingredient of a successful network (Vangen and Huxham, 2010). Positive interactions within a network community rely upon trust, equity and reciprocity that enhances social capital and thus shapes the quality of the network and the learning that occurs within it (Casey, 2011; Putnam, 2000). The concept of social capital is not new with a range of specialist literature in this field and notable theorists who have explored the concept in depth (Coleman, 1988; Bourdieu and Wacquant, 1992). This paper bases the notion of social capital on one of the most prominent theorists in the field, Putnam (1995). He provides clear distinctions between the positive and negative impact of social capital and this is pertinent to outcomes of work-related learning networks.

Putnam (1993) defines social capital as "the features of social organization such as networks, norms, and social trust that facilitate coordination and cooperation for mutual benefit" (167). The interrelated features of trust, networks and norms are essential aspects of social capital. Trust facilities cooperation, and the more individuals trust others and feel that this trust is reciprocated the greater the likelihood of cooperation between them, for example within a nursing network. Reciprocity is key within a network because if participants believe that 'good acts' or pro-social behaviour will be reciprocated at a later point social capital will be enhanced (Field, 2013). Whilst personal interactions within a network enable someone to learn about the trustworthiness of another, the network is important to allow information about a person's trustworthiness to travel more widely (Vangen and Huxham, 2010). Furthermore, the denser the social interactions the greater the social capital within a network that can foster robust norms of reciprocity and sustain information about past collaborative success. Strong social capital also results from flatter or more horizontal network structures whereas hierarchical networks detract from it. Social capital as an explanatory framework also considers the connections within networks as a form of capital that link the micro level of the individual and the meso level of the network (Field, 2008). Putnam (2000) identifies various distinctions of social capital, firstly there are looser ties known as bridging capital which relies upon more remote connections with a focus on gathering contacts and access to information with minimal interaction and support. Secondly is bonding social capital which provides a more intense form of support (Halpern, 2005). Putnam (2005:23) suggests that bonding and bridging are not 'either-or' categories but rather 'more or less' dimensions which can exist within a single network.

Social capital as defined by Putnam (1993) was therefore used to understand how the network and its practice in this study could be understood, it was used as a lens to examine participants' practice and their accounts of their learning and professional development as a result of participating in the network.

\section{Nurse educator networks}

Network activity is common within the nurse education sector particularly across Europe with established networks claiming to share knowledge, resources and support (Koskinen et al., 2012b; 
Burgess, Reimer-Kirkham and Astle, 2014; Coates and Fraser, 2014). This has evolved from the internationalisation agenda of Higher Education Institutions with universities using such network engagement to globalise their university (Ottewill, 2005; Coryell et al., 2012; Wakefield and Dismore, 2015). Universities rely on these networks and collaboration to expand through increasing strategic advantage and provide wider educational opportunities for their students and staff, which also includes transnational opportunities (Donert et al., 2011; Fell, Fell and Kyoung, 2012; Wakefield and Dismore, 2015). These influences are also significant within the field of nurse education (Law and Muir, 2006; Koskinen et al., 2012a; Burgess et al., 2014).

Organisations in the educational and health care sector perceive that networking conveys collaborative advantage and improves collective agency (Koschmann, Kuhn and Pfarrer, 2012). However, for an educational network to be successful there is a requirement to have some form of process orientated structure which includes a common focus that all participants agree with, a clear governance structure and communication strategy. Muijs (2011); Azorín and Muijs (2017) identify the need for structured working and quality assurance, otherwise poor performance or weak collaboration by any organisation involved can lead to a failure of the network. Furthermore, there is an expectation that participants are motivated to engage with the networking partners so that strong equitable and inclusive relationships are created (Bienzle et al., 2007; Muijs et al., 2010; Casey, 2011; Sousa et al., 2013; Ovseiko et al., 2014). However commitment to the network is not enough if the power dynamics are unbalanced (Huxham and Vangen, 2005) with the result that the network does not achieve its full potential and at worst becomes dysfunctional. On the other hand, the features of effective networks are synergistic with other socially functioning groups that display high levels of social capital (Muijs et al., 2010).

\section{Outcomes and value of participating in a network.}

There are clear resource benefits from developing collaborative advantage and sharing of resources across networks. Networks also have other benefits which are learning and innovative in focus with an emphasis on professional development for individuals involved (Wakefield and Dismore, 2015), this is perceived to result in organisational improvement (Muijs et al., 2010). Certainly professional development from engaging in networks has been identified as being influential in developing academic practices within schools and the Further Education sector (Centre for the Use of Research and Evidence in Education, 2005; Appleby and Hillier, 2012). Members within this network are identified as nurse educators, this term is used as it encompasses the range of titles used globally for the role which include nurse academic, nurse teacher, nurse lecturer and nurse faculty member. The nurse educator in this context is a person who delivers and oversees education predominately delivered in a higher education setting or equivalent. For the purpose of this study, informal learning or professional development is framed with the concept of scholarly practice which is based on the definition by Boyer (1990) who proposed that within higher education a broader perspective of 'scholarship' should be used rather than the dualism of teaching/research. The nurse educator undertakes many other activities as part of their nexus of practice which includes cross boundary activity such as working in teams, having a clinical focus and quality assurance. The broader term of scholarly practice acknowledges a broader approach whereby research, scholarship, teaching and learning are part of one seamless whole (Boud and Brew, 2013b). Scholarly practice has four distinct yet overlapping meanings: the scholarship of discovery, the scholarship of integration, the 
scholarship of application, and the scholarship of teaching; this perspective has been supported by the American Nurses Association (American Association of Colleges of Nursing, 1999).

\section{The study}

The purpose of this study was to explore the working practices of a European Nurse Education Network which involved investigating the nature of the relationships and collaborations established within the network, with a scrutiny of how this may facilitate learning and professional development of the members. In this context the network refers to face-to-face encounters as well as online correspondence between member.

\section{Research design}

This research is positioned within an interpretive paradigm with interpretivism being the conceptual anchor whereby assumptions of knowledge are constructed through lived local experiences and through interactions with others. This paradigm also recognises the influence the researcher has on the interpretation of the situation (Guba and Lincoln, 1989). Interpretivism guided the methodology of this embedded single case study which adopted an iterative and holistic design involving three stages (Yin, 2014).

\section{The case}

In this research the single case was the network with data gathered over a two-year period where all members within the network at the time were within the bounded unit and invited to participate. The longitudinal nature of the case study allowed an in-depth understanding of the situation to develop and the opportunity to explore different perspectives over time (Hamilton and CorbettWhittier, 2012).

\section{Data Collection Methods}

The first stage utilised a focus group that assisted in framing the subsequent stages of data collection and to gain an understanding of how participants conceptualised the network. The focus group enabled the participants ' world views, both individually and as a group, to be gathered about their opinions of the network, and the meaning it had for them. To gather this information, a structured focus group schedule was used with the findings framing the second stage of data collection.

The next stage analysed the documents that were created by the network which offered the opportunity to explore and appraise meaning that was attached to these items. The analysis included an interpretation of the written practices of the individuals, as well as their relationships with each other and the community. The documents such as annual meeting minutes and guidelines were authentically composed by the participants; a purposeful sample of the documents were analysed based on the critical moments of the lifespan such as new leadership or a change of governance processes or increased student activity (Mcculloch, 2004).

The final stage of data collection utilised semi-structured interviews with self-selected members of the network. This method offered the opportunity to understand the experiences and perceptions of the nurse educators involved in the network using a naturalistic and interpretative framework (Rubin and Rubin, 2005; Denzin and Lincoln, 2013). 


\section{Participant sample in the research}

All members of the network (approximately 30 ) were invited to contribute to the focus group and interviews via email; data collection was undertaken during the annual meetings of the network. The focus group participants involved eight self-selected members from a range of countries, all with a range of experiences. There were a further eight volunteers for the semi-structured interviews with five of the sample having participated in the focus group as they felt that they wanted the opportunity to continue to discuss their perspectives in more depth.

\section{Data Analysis}

Data were collated at different stages and all data was imported into NVivo 10 software (Qsr, 2013) and analysed iteratively. Sets were coded to manage this data as it facilitated the development of interpretations by keeping track of ideas as they occurred and assisted with organising and displaying the data. A cross-case analysis was undertaken with the data sets whereby duplication of categories was considered, noting relations of variables identified with potential themes explored. Thematic analysis was supported by Braun and Clarke (2006).

Approval was gained from the university ethics committee with special attention paid to informed consent; minimizing the potential for coercion and ensuring privacy and confidentiality.

\section{Findings}

Three clear themes emerged from the data which are a) the practice of network, b) the participants' learning, c) exclusivity and status quo. The first theme frames the latter two due to the suggested influence of by-products from engaging in the practice of the network on participants learning and the exclusivity exhibited by the network.

\section{Practice of the network}

Practice in this context relates to the activity within the network which enables the network to function to sustain itself. The practice of the network has produced artefacts, rituals and rules all of which have structured the workings of the network, as such these have become significant as a framework to sustain the network activity. The collective nature of the group is identified as important and is given value by the network through the requirement to deliver and attend annual meetings; these meetings have a focus on processes within network activity rather than a wider strategic network development. Wider literature suggests that this activity reflects a structure of a transnational co-operative project rather than strategy focused networks which have been more traditional across Europe (Bienzle et al., 2007).

Early focus group data provided a portrait of this network which suggested the activity to be underpinned with a purpose of pragmatism and function which was responsive to the needs of the individual organisations involved in securing student exchange opportunities. This was reinforced by individual perceptions of how the network functions: 


\begin{abstract}
'My point of view, the whole idea of the network is to give students the opportunity to gain some experience. So, I think that's really what we're aiming for. Giving students this opportunity. 'Int-1: $\mathbf{2 3}^{\mathbf{1}}$
\end{abstract}

Through the collective of the network collaborative advantage has been established to secure placement provision across a range of providers, and the focus of the network has been to sustain and focus this activity. The documentary analysis reinforces this with evidence of governance and organisational structures which have evolved over time and have become embedded within the practices. These are the artefacts, rituals and rules which have become an integral aspect of the network practice. They have been instrumental in the achievement of student exchange rather than in achieving other espoused aims of research collaboration which are often cited within strategic networks. A key activity of this network has been the annual conferences which serves to monitor and reinforce the governance structures and embed a common understanding of the network across a range of members, organisations, cultural and political context. The annual meetings utilised formulaic rituals of showcasing individual organisations hosting the event particularly in countries where culturally hierarchy and associated status is important (Hofstede, 2001).

'Also, XXX, member of the XXX institution formally opened the conference, she then gave a presentation of the different facilities ' $X X X X$ Report: Section $1.01^{2}$

Artefacts produced reinforce these practices with the example being of the use of a 'handbook' outlining the rules and regulations of participation. This artefact is identified as being integral to the practice of network.

'And if we didn't have the handbook, I think it would all fall apart. It's all written, it hasn 't changed much` Int-1:45

These practices over time have served to create a specific type of culture associated to the network engagement and this was recognised by the participants in the interviews

'The Network is a system with its own way of going on and its own self-built culture. I think this has arisen to cope with the many differences`Int-2-66

Standardisation of process and practice was thought to be needed to be able to mediate the cultural and language differences that occur within a cross European network. However, this was not perceived by the participants as being useful with the notion that these artefacts and subsequent practice was problematic as indicated by this quote:

'The difficulties are that, even if we meet every year and we have this handbook, the cultural differences sometimes make it difficult' Int-4:70

Clearly working across different cultures was perceived as a challenge and was identified at times as being problematic within this network, even though various participants expressed frustration they

\footnotetext{
1 Interviewee 1 : line number 23

2 Date/report: location in document
} 
appeared to accept the culture, rules, artefacts and practice of the network. Their frustrations seem to have been less important compared to the systems, structures and rituals of the network e.g. the structure of annual meetings.

\section{Connectedness and Social Capital}

The annual meetings provide the structure to develop connections and social capital and this ritual was identified as being important:

'Because that's why we meet every year, to make sure the network works' Int-1:25

That the relationships developed from a regular meeting alongside having the familiarity of systems, structure and rituals provides a sense of stability which serves to promote the practice of the network and subsequent exchange activity:

'Because it makes you feel comfortable. It makes you trust people. And if you trust people, it`s easier to give that trust to your students' Int-3:21

Trust is identified repeatedly both in the focus group and within the interviews as being essential for the practice of the network to success and as being key for the relationships to work. Trust has developed the collective responsibility and collegiate relationships. The following experienced participant reflects on her involvement with the network; how she perceived her interaction with members of the network by using terms such as 'feeling part' and 'together' that illustrate the existence of social capital, and collective responsibility, that is manifested within the network:

'I mean that people feel they are part of it, not just organising. They feel they really after a while you feel you kind of own the network together with the others`Int-4:23

There are clearly strong ties amongst the participants which serve to strengthen social capital, more specifically this is a form of social capital known as bonding capital. Bonding capital tends to occur across a homogenous and dense network of people and tends to be exclusive in providing support to members of the network (Putnam, 2000). This is illustrated by a sense of kinship described as being important, and that the regular meetings were an opportunity to meet 'cousins' (Int-1:23). This has been reinforced by the policies of the network as illustrated by the mentoring within the network

'XXX suggests a godmother/father/mentor system for new member' 2 XXX report: Section 5.2

From developing mentoring and orientation to the network then bonding capital is created which serves as an intense form of support (Halpern, 2005), but in this particular network has created an interesting juxta-position of both positive and negative effects both created by strong bonding capital.

\section{Participant learning}

The findings from the focus group and the interviews identified a perception that professional development occurred due to the strong bonding social capital within the relationships.

'I think it's so fundamental. It's through being connected, that we learn, that we feel we are not on our own. But we learn a lot. It provides safety, its provided continuance. It provides the possibility to develop. To grow. ' Int-2: 118 
This connectedness was perceived as providing intense support from the network for individual participants in their own professional domain, more specifically within the scholarship of integration and application which is solipsistic in nature and involves application to the practice of teaching (American Association of Colleges of Nursing, 1999). Participants identified that they entered the network hoping that they might develop their scholarly practice, and this has been expressed as an individual beneficial gain.

Across the network there was a sense of sharing of knowledge or scholarship in presentations related to professional nursing practice and from peers at the annual meetings. This is illustrated by the following example, and there is evidence of similar sharing at previous annual meetings with presentations included in the minutes:

'The Friday session began with an interesting talk given by Ms XXXXX, on the topic:

"Practice development - how to improve self -management support"?

20XX report: Section 13

These incidences appear to have had an impact on participants, with one participant reflecting in her interview on becoming more aware of a strand of developing academic activity:

'I don't know which conference it was but two or three conferences ago we had some world expert come and talk to us for an hour about global health. And that's something definitely that we don't have in our curriculum. We do health promotion. She was really good, this speaker. She was really good at showing how it does affect us and we do need to become aware, and perhaps we should be including it in our curriculum a bit more and more understanding` Int-6:128

Development of scholarly teaching is evident across the participant interviews which has been gained through observation, discussion and experiences within the network:

'You see different teaching styles; you see different approaches and we learn from each other. Int-3:228

'Two years ago, we were in XXX, and I saw their equipment and when I came back home I don't have the same equipment I try to do the same thing. And now in my teaching I'm using the equipment that is good. 'Int-5:212

The latter comment is relevant as it implies that prior to attending the network the use of teaching strategies may not have been used within the local curriculum. The same participant earlier indicated the need for their institution to gather different pedagogic teaching strategies as part of their involvement with the network. Other wider dimensions of learning occurred which is in alignment with scholarship or integration such as developing cultural awareness, personal learning and increased confidence. However, there was no recognition of learning from research activity. 
In summary, personal learning and scholarly development has occurred as consequence of strong bonding capital which has arisen from the practices within the network, and that social capital is a conduit for informal learning. This has been articulated as occurring predominately in three scholarly domains for each participant, with the potential to develop some in the fourth. Within this work context, bonding social capital is identified as a learning factor and integral for work related learning. Much of this learning appears to have occurred at a personal level in both confidence in trying new practices and developing cultural awareness and global understanding:

'So it's given me a broader view and personally being in the network has probably developed me in to being more aware`Int-1: 105

\section{Exclusion and collaborative inertia.}

These dense relationships can be problematic too, in this instance, having resulted in a practice within the network which is complex. Alongside the overt practices of the annual meeting and ceremonies, it has created a culture which is characterised by norms, values and expectations that are not explicitly articulated. There is an implicit nature of understanding of the network expected amongst the network participants. In this respect the network resembles a clan, or tribe with its collective and implicit understanding of what it means to belong to the group and this behaviour is common within professionals whereby hidden rules are in place to enculture newcomers to the profession (Becher and Trowler, 2001). This was perceived by the participants in interviews with the following quote which illustrates how newcomers are expected to take time to understand the implicit culture of the network the expected behaviour associated with this.

'You've got little cliques, and you're either welcomed in or you're not'. You do need to take time to integrate yourself and become aware of how the group works, how things operate before you go in and perhaps too heavy handed. 'Int-6:22

This participant felt that they needed to be accepted by the group with a hidden gatekeeping mechanism and rite of passage for admission to decision making. Those that do not understand the language or culture/rules of the group are then not able to contribute to any decision making, and they are essentially excluded. Certainly, in such groups with their strong social capital bonding there is a tendency for exclusivity and a reluctance to change its way of working, previously identified as collaborative inertia (Vangen and Huxham, 2010). The following quote identifies the established network practices that are not only complex and seemingly contradictory but that when new ideas are suggested about how to alter these practices it highlights the inertia to any change that may be suggested.

'But they want to do it in a particular way. They come in with a whole set idea that this is what they want to put forward to the network. But the way of working is, "Okay, bring it into the group work to discuss it, and be challenged about it and let us make it our own thing. As soon as something has been put upon it, the network almost explodes, like we don't want to have it. And that is, in itself an interesting thing. It's not only that we don't want it, but why are we so strong in opposing that way? And even to the point of, it's very hard to really talk about it'. Int-2:58 
This quote illustrates the collaborative inertia of the network which can occur when the power relations within the network disable the notion of openness, debate and cross-cultural compromise which can lead to hidden practices to avoid conflict. That consequently no new ideas are developed as illustrated by the limited expansion of the network over a number of years and perceived as inertia by the participants of the study.

'We don't go further on, new people are coming and I think it is naturally that new people are coming, but again the steps are not taken forward and this is more difficult so they do not stay`. Int-8:52

\section{Discussion}

Using social capital as a framework to understand the working practices and learning within a nursing education network is a useful approach, social capital is integral to the practice of this network and has been influential in its development and the learning exhibited by the participants. Understanding the network practice and activities mediated through social capital suggests that there is an ebb and flow of positive and negative consequences. Positive outcomes are the sustained partnerships within the network which maintains the practice of the network, a phenomenon which has been identified as important to maintain and sustain the network without financial capital (Billett et al., 2007; Dhillon, 2009). Social capital is positively associated with influencing high levels of performance or outcomes (Field, 2005; Halpern, 2005; Field, 2008). The network is productive in securing student placements across Europe in response to wider internationalisation antecedents. Finally, through the creation of social capital in the practice of the network, there is evidence of self-governance and distributed leadership, which contributes to sustaining practices.

More specifically social capital through the strong bonding capital established appears to create a learning milieu for the participants as a result of the trust created between participants. Being connected was identified by participants as being fundamental to their personal development and learning. Two specific sub-ordinate themes are relevant here; the first identifies that learning and professional development has been gained which is considered using Boyers 'scholarship domains (1990) and the second involves identifying what learning factors contribute to this. A learning factor affects learning either directly or indirectly and can be evidenced within formal learning settings such as the classroom or within informal learning settings such as a work context (Eraut, 2006). Engaging in this network is a work activity and provides an informal learning setting for its members, this network practice has provided opportunity for learning and academic practice (Cairns and Malloch, 2011; Boud and Brew, 2013a). Therefore, the European Nurse Education Network is providing an informal learning opportunity.

Social capital also has created an interesting juxtaposition in the network whereby the strong bonding capital established also has created negative consequences which appear to perpetuate exclusivity and compliance. Rituals and rules have been established whereby participants perceive they have had to adapt their behaviour to ensure they are accepted by the group and there is a need 
for compliance with cultural norms. A level of exclusivity is present which is managed by long term members to sustain the status quo. It is well understood that strong bonding networks which have limited external influence can develop coercive behaviours and occurs through a typology of compliance in relationships which have become established due to strong bonding social capital. (Field, 2008). Putnam (2000) describes this as being a 'dark side' of social capital which is present in this network. The static and enclosed nature of the network has led to an inertia and lack of growth and development which has created frustration for some of the participants. This has led to the network's activity being exclusive, homogenous and used for 'getting by 'rather than 'getting ahead' (Putnam 2000:23). Huxham and Vangen (2004) alternatively suggest that those who engage in multiple collaborative partnerships become fatigued by the multiple partnership activity expected of them which presents itself as an inertia within the partnership.

The ebb and flow of social capital indicates the equally negative and a positive effect on learning. In this case study, bonding social capital is a learning factor that enhances both learning and encourages a commitment to the network that has ensured some development in the scholarly practice of the participants (Hargreaves and Fullan, 2012). On the other hand, strong bonding social capital has simultaneously stifled the development of new ideas or new areas for learning. This is an interesting finding and contributes to the minimal understanding of the production and maintenance of social capital in the field of adult education and more particularly nurse education (Mcclenaghan, 2003; Field, 2008).

\section{Conclusion}

This research adds to the understanding of work-related learning theories; particularly where strong bonding social capital within a group exists and this appears to be influential on the learning of its members. Network activity in nurse education has not been significantly researched despite the plethora of networks in existence; therefore, these findings provide an interesting insight into how networks may function. It is recognised that further investigation of nurse education work practices is needed as this is identified as complex and unique with educators often experiencing feelings of uncertainty and isolation (Jackson et al., 2009; Duffy, 2012; Mcdermid et al., 2013; Mcdermid et al., 2016). This study offers a new perspective illustrating that bonding social capital could also be a useful resource to sustain nurse education networks and provide individual positive learning experiences. Through proactive development of social capital within partnerships and networks, activity could be sustained and become influential with the potential for positive outcomes. The findings also illustrate the risks of bonding social capital that creates embeddedness in conjunction with a reliance on internal self-governance that contributes towards exclusivity and inertia. The repercussions of this are that the network is bounded, without growth or evolution, and is exclusive and can be very difficult to enter for some prospective participants.

This small-scale study offers an insight into the importance of social capital as learning factor which is applicable for wide range of settings. Further research is needed in this field both to identify how social capital, which is created through work related activities and collaborative activities, may be a useful conduit to scaffold learning for learners not engaged in formal learning settings and to more fully understand the negative consequences of social capital that can lead to inertia and exclusion.

\section{References}


American Association of Colleges of Nursing. 1999. Defining Scholarship for the Discipline of Nursing [Online]. Available: http://www.aacn.nche.edu/publications/position/defining-scholarship [Accessed 14.11.16].

Appleby, Y. \& Hillier, Y. 2012. Exploring practice - research networks for critical professional learning. Studies in Continuing Education, 34, 31-43.

Azorín, C. M. \& Muijs, D. 2017. Networks and collaboration in Spanish education policy. Educational Research, 59, 273-296.

Baum, J. \& Rowley, T. 2008. Network strategy, Bingley, U.K, Emerald.

Becher, T. \& Trowler, P. 2001. Academic tribes and territories: intellectual enquiry and the culture of disciplines, Buckingham, The Society for Research into Higher Education \& Open University Press.

Bienzle, H., Gelabert, E., Jütte, W., Kolyva, K., Meyer, N. \& Tilkin, G. 2007. The Art of Networking, Austria, die Berater.

Billett, S., Ovens, C., Clemans, A. \& Seddon, T. 2007. Collaborative working and contested practices: forming, developing and sustaining social partnerships in education. Journal of Education Policy, 22, 637-656.

Boud, D. \& Brew, A. 2013a. Reconceptualising academic work as professional practice: implications for academic development. International Journal for Academic Development, 18, 208-221.

Boud, D. \& Brew, A. 2013b. Reconceptualising academic work as professional practice: implications for academic development. The International Journal for Academic Development, 18, 208.

Bourdieu, P. \& Wacquant, L. C. J. D. 1992. An invitation to reflexive sociology, Cambridge, Polity Press.

Boyer, E. L. 1990. Scholarship reconsidered: Priorities of the professoriate, Princeton, N.J, The Carnegie Foundation for the Advancement of Teaching.

Braun, V. \& Clarke, V. 2006. Using thematic analysis in psychology. Qualitative Research in Psychology, 3, 77-101.

Burgess, C. A., Reimer-Kirkham, S. \& Astle, B. 2014. Motivation and international clinical placements: Shifting nursing students to a global citizenship perspective. International Journal of Nursing Education Scholarship, 11, 75-82.

Cairns, L. \& Malloch, M. 2011. Theories of Work, Place and Learning: New Directions. In: Malloch, M., Cairns, Len., Evans, Karen. \& O`Conner, Bridget (ed.) The Sage Handbook of Workplace Learning. Sage.

Casey, M. 2011. Interorganisational partnership arrangements: A new model for nursing and midwifery education. Nurse Education Today, 31, 304-8.

Centre for the Use of Research and Evidence in Education 2005. Systematic research review: The impact of networks on pupils, practitioners, organisations and the comittess they serve., Nottingham, National College of School Leaders

Coates, K. \& Fraser, K. 2014. A case for collaborative networks for clinical nurse educators. Nurse Education Today, 34, 6-10.

Coleman, J. S. 1988. Social capital in the creation of human capital. American Journal of Sociology, 94, S95-S120.

Connolly, M., Jones, C. \& Jones, N. 2007. Managing collaboration across further and higher education: a case in practice. Journal of Further and Higher Education, 31, 159-169.

Coryell, J. E., Durodoye, B. A., Wright, R. R., Pate, P. E. \& Nguyen, S. 2012. Case studies of internationalization in adult and higher education: Inside the processes of four universities in the United States and the United Kingdom. Journal of Studies in International Education, 16, 75-98.

Denzin, N. K. \& Lincoln, Y. S. 2013. Collecting and interpreting qualitative materials, London, Sage.

Dhillon, J. K. 2009. The role of social capital in sustaining partnership. British Educational Research Journal, 35, 687-704. 
Donert, K., Hay, I., Theobald, R., Valiunaite, V. \& Wakefield, K. 2011. International collaboration in organizations promoting geography education: Exploring success and acknowledging limitations. Journal of Geography in Higher Education, 35, 445-455(11).

Duffy, R. 2012. Nurse to educator? Academic roles and the formation of personal academic identities. Nurse Education Today.

Eraut, M. 2006. Learning contexts. Learning in Health and Social Care, 5, 1-8.

Eraut, M. 2007. Learning from other people in the workplace. Oxford Review of Education, 33, 403422.

Fell, D. W., Fell, D. W. \& Kyoung, K. 2012. Developing international collaborations in physical therapy academia: a case example emphasizing education and scholarship.

Field, J. 2005. Social capital and lifelong learning, Bristol, Policy Press.

Field, J. 2008. Social capital, Abingdon, Routledge.

Field, J. 2013. Learning communities and imagined social capital: learning to belong. ABINGDON: ROUTLEDGE JOURNALS, TAYLOR \& FRANCIS LTD.

Fleming, J. \& Haigh, N. J. 2018. Using sociocultural insights to enhance work-integrated learning. Higher Education, Skills and Work-Based Learning, 8, 395-407.

Guba, E. G. \& Lincoln, Y. S. 1989. Fourth Generation Evaluation, Newbury Park, California, Sage.

Halpern, D. 2005. Social capital, Cambridge, Polity.

Hamilton, L. \& Corbett-Whittier, C. 2012. Using case study in education research, London, SAGE.

Hargreaves, A. \& Fullan, M. 2012. Professional capital: transforming teaching in every school, New York, Teachers College Press.

Hofstede, G. H. 2001. Culture's consequences: Comparing values, behaviors, institutions, and organizations across nations, Thousand Oaks, California Sage

Huxham, C. 1996. Creating collaborative advantage, London, SAGE.

Huxham, C. \& Vangen, S. 2004. Doing things collaboratively: Realizing the advantage or succumbing to inertia? Organizational Dynamics, 33, 190-201.

Huxham, C. \& Vangen, S. 2005. Managing to collaborate: the theory and practice of collaborative advantage, London;New York; Routledge.

Jackson, C., Bell, L., Zabalegui, A., Palese, A., Sigurđardóttir, Á. K. \& Owen, S. 2009. A review of nurse educator career pathways; a European perspective. Journal of Research in Nursing, 14, 111122.

Koschmann, M. A. \& Kuhn, T. R. 2012. A communicative framework of value in cross-sector partnerships. The Academy of Management review, 37, 332-354.

Koschmann, M. A., Kuhn, T. R. \& Pfarrer, M. D. 2012. A Communicative Framework of Value in CrossSector Partnerships. Academy of Management Review, 37, 332-354.

Koskinen, L., Kelly, H. T., Bergknut, E., Lundberg, P., Muir, N., Olt, H., Richardson, E., Sairanen, R., De Vlieger, L., Medicinska Och Farmaceutiska, V., Uppsala, U., Vårdvetenskap, Medicinska, F. \& Institutionen För Folkhälso- Och, V. 2012a. European Higher Health Care Education Curriculum: Development of a Cultural Framework. Journal of Transcultural Nursing, 23, 313319.

Koskinen, L., Kelly, H. T., Bergknut, E., Lundberg, P., Muir, N., Olt, H., Richardson, E., Sairanen, R., De Vlieger, L., Vårdvetenskap, Uppsala, U., Medicinska Och Farmaceutiska, V., Institutionen För Folkhälso- Och, V. \& Medicinska, F. 2012b. European higher health care education curriculum: development of a cultural framework. Journal of transcultural nursing : official journal of the Transcultural Nursing Society / Transcultural Nursing Society, 23, 313-319.

Law, K. \& Muir, N. 2006. The internationalisation of the nursing curriculum. Nurse Education in Practice, 6, 149-155.

Mcclenaghan, P. 2003. Response to 'social capital: an analytical tool for exploring lifelong learning and community development'. British Educational Research Journal, 29, 435-439.

Mcculloch, G. 2004. Documentary research in education, history and the social sciences, London, RoutledgeFalmer. 
Mcdermid, F., Peters, K., Daly, J. \& Jackson, D. 2016. Developing resilience: Stories from novice nurse academics. Nurse Education Today, 38, 29.

Mcdermid, F., Peters, K., John Daly, J. \& Jackson, D. 2013. 'I thought I was just going to teach': Stories of new nurse academics on transitioning from sessional teaching to continuing academic positions. Contemporary Nurse, 45, 46-55.

Muijs, D. 2011. Leadership and organisational performance: From research to prescription? International Journal of Educational Management, 25, 45-60.

Muijs, D., West, M. \& Ainscow, M. 2010. Why network? Theoretical perspectives on networking. School Effectiveness and School Improvement, 21, 5-26.

Nevalainen, M., Lunkka, N. \& Suhonen, M. 2018. Work-based learning in health care organisations experienced by nursing staff: A systematic review of qualitative studies. Nurse Education in Practice, 29, 21-29.

Ottewill, R., . Riddy, P,. Fill,. K. 2005. International Networks in higher education: realising their potential. Horizon, 13, 138 - 147.

Ovseiko, P. V., O'sullivan, C., Powell, S. C., Davies, S. M. \& Buchan, A. M. 2014. Implementation of collaborative governance in cross-sector innovation and education networks: evidence from the National Health Service in England. BMC health services research, 14, 552-552.

Putnam, R. D. 1993. Making democracy work:civic traditions in modern Italy, Princeton, Princeton University Press.

Putnam, R. D. 2000. Bowling alone: the collapse and revival of American community, New York, Simon \& Schuster.

Qsr, I. 2013. Nvivo 10 for Windows [Online]. [Accessed 10.10. 2013].

Rubin, H. J. \& Rubin, I. 2005. Qualitative interviewing: The art of hearing data, Thousand Oaks, California, Sage Publications.

Sousa, S. B., Doroftei, A. O. \& Araújo, H. C. 2013. Networks in education: An analysis of selected discourses. Interchange, 44, 311-331.

Vangen, S. \& Huxham, C. 2010. Introducing the theory of collaborative advantage. In: Osborne, S. (ed.) The New Public Governance? Emerging perspectives on the theory and practice of public governance. London: Routledge.

Wakefield, K. \& Dismore, H. 2015. The role of transnational networking for higher education academics. Higher Education Research and Development, 34, 1281-1296.

Wei, L.-Q., Chiang, F. F. T. \& Wu, L.-Z. 2012. Developing and utilizing network resources: Roles of political skill. Journal of Management Studies, 49, 381-402.

Yin, R. K. 2014. Case study research: design and methods, London, Sage. 